Poster Section

\title{
Development of a biocrystallisation assay for examining effects of homeopathic preparations using cress seedlings
}

\author{
Stephan Baumgartner 1,2,3 , Paul Doesburg 4,5, Claudia Scherr ${ }^{1,2}$, \\ Jens-Otto Andersen ${ }^{6}$
}

${ }^{1}$ Institute of Complementary Medicine KIKOM, University of Bern, Switzerland, ${ }^{2}$ Hiscia Institute, Arlesheim, Switzerland

${ }^{3}$ Center for Integrative Medicine, University of Witten/Herdecke, Germany

${ }^{4}$ Louis Bolk Institute, Driebergen, the Netherlands

${ }^{5}$ Present address: Crystal Lab, Ottersum, the Netherlands

${ }^{6}$ Biodynamic Research Association Denmark, Galten, Denmark

\begin{abstract}
Background: A major challenge of homeopathic basic research is to develop test systems that yield consistent results. Outcome of plant bioassays is usually based on growth parameters (e.g. germination rate, seedling length, leaf area).

Aims: We aimed to evaluate the potential of a crystallisation method with additives ("biocrystallisation") as complementary outcome measure. This method used is based on the crystallographic phenomenon that when crystallising watery solutions of dihydrate $\mathrm{CuCl}_{2}$ in the presence of organic additives (juices/extracts), reproducible dendritic crystal structures are observed. The resulting biocrystallograms can be evaluated visually and/or by computerized image analysis.

Methods: Cress seeds (Lepidium sativum L.) germinated and grew in vitro in either Stannum met. 30x or water 30x. Per experiment, six coded (blinded) 30x preparations were applied in randomized order, representing three independent replicates of the two treatments. Seedlings grew for 96 hours in darkness and were subsequently processed into a watery extract. Biocrystallisation was performed on circular glass plates in 6 -fold replication per treatment group, yielding 36 biocrystallograms per experiment. A total of 15 independent experiments were performed at two independent laboratories. Biocrystallograms were scanned and analysed by computerized texture image analysis, using 15 second-order parameters as outcome measure. 3 -way-ANOVA with the independent parameters treatment $(n=2)$, internal replicate $(n=3)$, and number of experiment $(n=15)$ was used to analyse the data.
\end{abstract}

Results: All 15 texture analysis $(\mathrm{TA})$ variables yielded significant $(\mathrm{p}<0.05)$ or highly significant $(\mathrm{p}<0.01)$ results for the homeopathic treatment. 12 out of 15 second-order TA variables yielded significant $(p<0.05)$ or 
highly significant $(\mathrm{p}<0.01)$ statistical interactions between experimental day and potency treatment, meaning that the difference between Stannum met. 30x and water 30x seemed to exhibit varying results for different experimental days. Three out of $15 \mathrm{TA}$ variables did not show any such interaction meaning that the effects of Stannum met. 30x versus water 30x were quite reproducible over the 15 independent experiments for these three TA variables. Two variables yielded differences between the internal replicates $(p<0.05)$, most probably due to a processing order effect. There were only minor differences between the results of the two laboratories.

Conclusions: The texture of biocrystallograms of homeopathically treated cress exhibited specific characteristics, differentiating water 30x and Stannum met. 30x. Thus, the biocrystallisation method seems to be a promising complementary outcome measure for plant bioassays investigating effects of homeopathic preparations.

Keywords: Biocrystallisation, homeopathy, potentisation, Stannum metallicum (tin), Lepidium sativum L.

\section{(cc) EY-NC-ND Licensed to GIRI}

Support: The project group thanks the supporting foundations Bodil Petersen Fonden (DK), Ekhagastiftelsen (S), Phoenix Stichting (NL), Fonden af 1. juni 1962 (DK), Fonden af 1870 (DK), as well as the companies Allergica (DK) and Weleda $(\mathrm{CH})$ that made the present study possible. The sponsors had no influence on design and implementation of the experiments, nor on analysis and interpretation of the results, nor on the decision to write and to publish this abstract. The authors had full access to all the data in this study and take complete responsibility for the integrity of the data and the accuracy of the data analysis.

Conflict of interest: authors declare there is no conflict of interest

Received: 01 June 2012; Revised: 10 August 2012; Published: 30 September 2012.

Correspondence author Stephan Baumgartner, stephan.baumgartner@kikom.unibe.ch, www.kikom.unibe.ch

How to cite this article: Baumgartner S, Doesburg P, Scherr C, Andersen JO. Development of a biocrystallisation assay for examining effects of homeopathic preparations using cress seedlings. Int J High Dilution Res [online]. 2012 [cited YYYY Month dd]; 11(40):202-203. Proceedings of the XXVI GIRI Symposium; 2012 Sep 20-22; Florence (Italy). GIRI; 2012; Available from: http://www.feg.unesp.br/ ojs/index.php/ijhdr/article/view/569/609 